\title{
Monitoring of Wheat Scab Using the Specific Spectral Index from ASD Hyperspectral Dataset
}

\author{
Linsheng Huang, ${ }^{1}$ Hansu Zhang $\mathbb{D}^{1,2}$ Wenjuan Ding, ${ }^{1}$ Wenjiang Huang, ${ }^{1,2}$ \\ Tingguang $\mathrm{Hu}$, ${ }^{1,2}$ and Jinling Zhao ${ }^{1}{ }^{1}$ \\ ${ }^{1}$ National Engineering Research Center for Agro-Ecological Big Data Analysis \& Application, Anhui University, Hefei, China \\ ${ }^{2}$ Key Laboratory of Digital Earth Sciences, Institute of Remote Sensing and Digital Earth, Chinese Academy of Sciences, \\ Beijing, China \\ Correspondence should be addressed to Jinling Zhao; aling0123@163.com
}

Received 12 June 2019; Revised 22 September 2019; Accepted 10 October 2019; Published 11 November 2019

Academic Editor: Alessandra Durazzo

Copyright ( $) 2019$ Linsheng Huang et al. This is an open access article distributed under the Creative Commons Attribution License, which permits unrestricted use, distribution, and reproduction in any medium, provided the original work is properly cited.

\begin{abstract}
It is highly important to accurately monitor wheat scab and provide technical guidance for the crop pests and diseases. In this study, relevant analysis was performed among spectral reflectance, first-derivate data, and the disease severity data through ASD hyperspectral data. Two sensitive spectral wavelength ranges of $450-488 \mathrm{~nm}$ and $500-540 \mathrm{~nm}$ were selected. Then, a new wheat scab index (WSI) consisting of the two bands was proposed. The inversion models of the scab severities were comparatively built by unitary linear regression and multiple stepwise regression techniques. The results showed that the WSI had a significant linear relationship with severity of disease compared with other commonly used spectral indices. The fitting $R^{2}$, testing $R^{2}$, and RMSE were $0.73,0.70$, and 13.41 , respectively. The multiple stepwise regression model established using the WSI, $\mathrm{SD}_{\mathrm{g}} / \mathrm{SD}_{\mathrm{b}}, \mathrm{NBNDVI}$, and $\mathrm{SD}_{\mathrm{g}}$ as independent variables was better than the single-variable model. Our results suggest that WSI can be used to provide scientific guidance for monitoring and precise management of wheat scab disease.
\end{abstract}

\section{Introduction}

China is a big agricultural country with vast land and abundant agricultural resources. Wheat is the second largest food crop in China, and its planting area ranks second. During the growth period of wheat, the occurrence of some pests and diseases will seriously affect the yield and quality. As one of the seriously infected diseases, wheat scab caused by a variety of Fusarium is a widespread and global disease occurring in warm and high-humidity environments [1]. According to the statistics, when the severe occurrence of wheat scab disease is about $50 \% \sim 100 \%$, the yield can be reduced by $40 \%$ [2]. Conventional stress-detection methods depend on physiological and biochemical analysis by field pathologists or experienced people. They are usually destructive, time-consuming, and labor-intensive. It is difficult to adapt to the current urgent needs of large-scale, real-time monitoring, and forecasting of pests and diseases [3, 4].
Therefore, how to quickly and accurately monitor wheat scab is an urgent problem to be solved.

Studies have shown that [5] some spectral characteristics change when vegetation is stressed. For example, the red edge will move to the shortwave direction when a plant is suffering from stress, and it is called "blue shift." This phenomenon usually takes place with the displacements of only a few nanometers to twenty nanometers [6]. It is difficult to capture this displacement using the traditional wide-band remote sensing data with hundreds of nanometers wide. Conversely, hyperspectral data with abundant band information and high resolution were used to detect the spectral response to diseases in more studies [7]. Many scholars used the hyperspectral data to analyze the spectral reflectance and found the sensitive bands for disease identification. For example, Graeff et al. [8] pointed out that the six wavebands of $490 \mathrm{~nm}, 510 \mathrm{~nm}, 516 \mathrm{~nm}, 540 \mathrm{~nm}$, $780 \mathrm{~nm}$, and $1300 \mathrm{~nm}$ could produce significant spectral 
responses to wheat powdery mildew. Huang [9] proposed that the spectral regions of $630-687 \mathrm{~nm}, 740-890 \mathrm{~nm}$, and 976-1350 nm were sensitive to stripe rust. Delwiche and Kim [10] found that wheat scab could cause spectral responses at $550 \mathrm{~nm}, 568 \mathrm{~nm}, 605 \mathrm{~nm}, 623 \mathrm{~nm}, 660 \mathrm{~nm}, 697 \mathrm{~nm}, 715 \mathrm{~nm}$, and $733 \mathrm{~nm}$. Different plants have different spectral characteristics, but the same plant may have different spectral characteristics at different growth stages and environments [7]. The response of the spectra to changes in plant physiology, biochemistry, morphology, and structure is highly complex. It is sometimes difficult to reflect the corresponding information accurately only through the initial spectral reflectance. Some more specific spectral indices can be proposed based on the hyperspectral data.

The spectral index can realize the identification and monitoring of different diseases by filtering and combining original bands. Bravo et al. [11] used the normalized difference vegetation index (NDVI) to extract the wheat stripe rust using discriminant analysis with an overall accuracy of over 95\%. Zheng et al. [12] proved that the three-band spectral indices PRI (570, 525, and $705 \mathrm{~nm})$ and ARI (860, 790, and $750 \mathrm{~nm}$ ) are optimal for monitoring yellow rust infection at different growth stages. Jiang et al. [13] found that the ratio of the first-order differential sum $\left(\mathrm{SD}_{\mathrm{r}}^{\prime}\right)$ in the red region $(725-735 \mathrm{~nm})$ to the first-order differential sum $\left(\mathrm{SD}_{\mathrm{g}}^{\prime}\right)$ in the green region $(520-530 \mathrm{~nm})$ is sensitive to the early symptoms of wheat disease. The correlation coefficient with the disease index reaches 0.921 , indicating the differential vegetation index $\mathrm{SD}_{\mathrm{r}}^{\prime} / \mathrm{SD}_{\mathrm{g}}^{\prime}$ is suitable for early diagnosis of wheat diseases.

Although many studies have been conducted on wheat disease, there is little research on scab. Most of the scholars used hyperspectral data to study stripe rust, powdery mildew, and aphid on leaf or canopy scale. Scab is a typical ear disease, so a proprietary index that can be used to monitor wheat ear-scale scab is desirable. Therefore, based on previous studies, our study aimed (1) to identify wavebands that are sensitive to wheat scab at ear scale; (2) to construct a new spectral index (WSI) for characterizing the spectral changes caused by scab infestation; and (3) to evaluate the performance of the proposed WSI for retrieving scab severities using linear regression method.

\section{Materials and Methods}

2.1. Study Site. The experiment was carried out at a test field in Guohe Town, Lujiang County, Anhui Province $\left(31^{\circ} 25.6^{\prime} \mathrm{N}, 117^{\circ} 9.2^{\prime} \mathrm{E}\right)$, on May 8,2018 (Figure 1). Rich water resources and suitable climate provide favorable conditions for the incidence of wheat scab, so the disease occurs almost every year. The wheat cultivars "Yangmai," "Ningmai," and "Wanxi" were selected as the experimental samples because of their moderate susceptibility to scab. The sowing time of wheat was around October 2017, and the harvesting time was around mid-June 2018. The test time was in GS stages when the scab showed severe infection.

2.2. Spectral Acquisition of Wheat Ear. The spectral reflectance of the wheat ear was collected with an ASD
FieldSpec Pro spectrometer (350-2500 nm) with the spectral resolution of $3 \mathrm{~nm}$ during the $350-1000 \mathrm{~nm}$ and $10 \mathrm{~nm}$ within the $1000-2500 \mathrm{~nm}$ range. Measurements were taken at sunny noon time $(10: 00-14: 00)$. During the measurement, every wheat ear was placed in the middle of the black cloth, and the probe of the sensor was held vertically downward to measure the upright, front, and side data. A $40 \mathrm{~cm} \times 40 \mathrm{~cm} \mathrm{BaSO}{ }_{4}$ calibration panel was measured to correct the reflectance. The spectra in different directions for each sample were measured 20 times, and then the mean was used as the reflectance. Hyperspectral data for the front, side, and upright sides of each wheat ear were finally determined. The calculation formula is as follows:

$$
R^{1}=\frac{\mathrm{DN}_{1}}{\mathrm{DN}_{2}} \times R^{2},
$$

where $R^{1}$ is the target reflectance, $\mathrm{DN}_{1}$ is the gray value of the target spectrum, $\mathrm{DN}_{2}$ is the gray value of panel, and $R^{2}$ is the panel reflectance.

2.3. Determination of Disease Severity. The disease severity is defined using the proportion of the infected spikelets to the total number. According to the rules for monitoring and forecast of wheat head blight (GB/T15796-2011), it is divided into 5 levels: Level $0(0)$, Level $1(0-1 / 4)$, Level $2(1 / 4-1 / 2)$, Level $3(1 / 2-3 / 4)$, and Level 4 (3/4-1).

In the experimental field, 41 sample plots were selected and an infected wheat was randomly selected as our research sample from each sample plot. A total of 41 infected wheat samples were obtained with different severity levels from the field survey (Figure 2). Each sample data was averaged from the front, side, and upright spectral reflectance. The healthy samples were not collected in this survey. According to the calculation of disease severity, the samples of levels 1-4 were $10,13,12$, and 6 , respectively. The spectral curve of wheat ears had serious noises after $1330 \mathrm{~nm}$, so the $350-1330 \mathrm{~nm}$ was selected in this study.

\subsection{Data Analysis}

2.4.1. Calculation of Spectral Differential. In order to analyze the spectral response characteristics of wheat scab, we averaged the sample spectral reflectance of each level. A correlation analysis was performed between spectral reflectance and disease severity was used to pick up the sensitive positions and ranges. However, due to the influence of noise, we failed to achieve good results through the original spectral reflectance. The spectral differential was used to reduce external influences, and its formula is as follows [14]:

$$
P^{\prime}\left(\lambda_{i}\right)=\frac{\left[P\left(\lambda_{i}+1\right)-P\left(\lambda_{i}-1\right)\right]}{2 \Delta \lambda},
$$

where $\lambda_{i}$ is the wavelength of the band $i, P^{\prime}\left(\lambda_{i}\right)$ is the differential value of $\lambda_{i}, P\left(\lambda_{i}+1\right)$ and $P\left(\lambda_{i}-1\right)$ are the previous and next spectral reflectance of $\lambda_{i}$, respectively, and $\Delta \lambda$ is the difference of $\lambda_{i-1}$ to $\lambda$. 


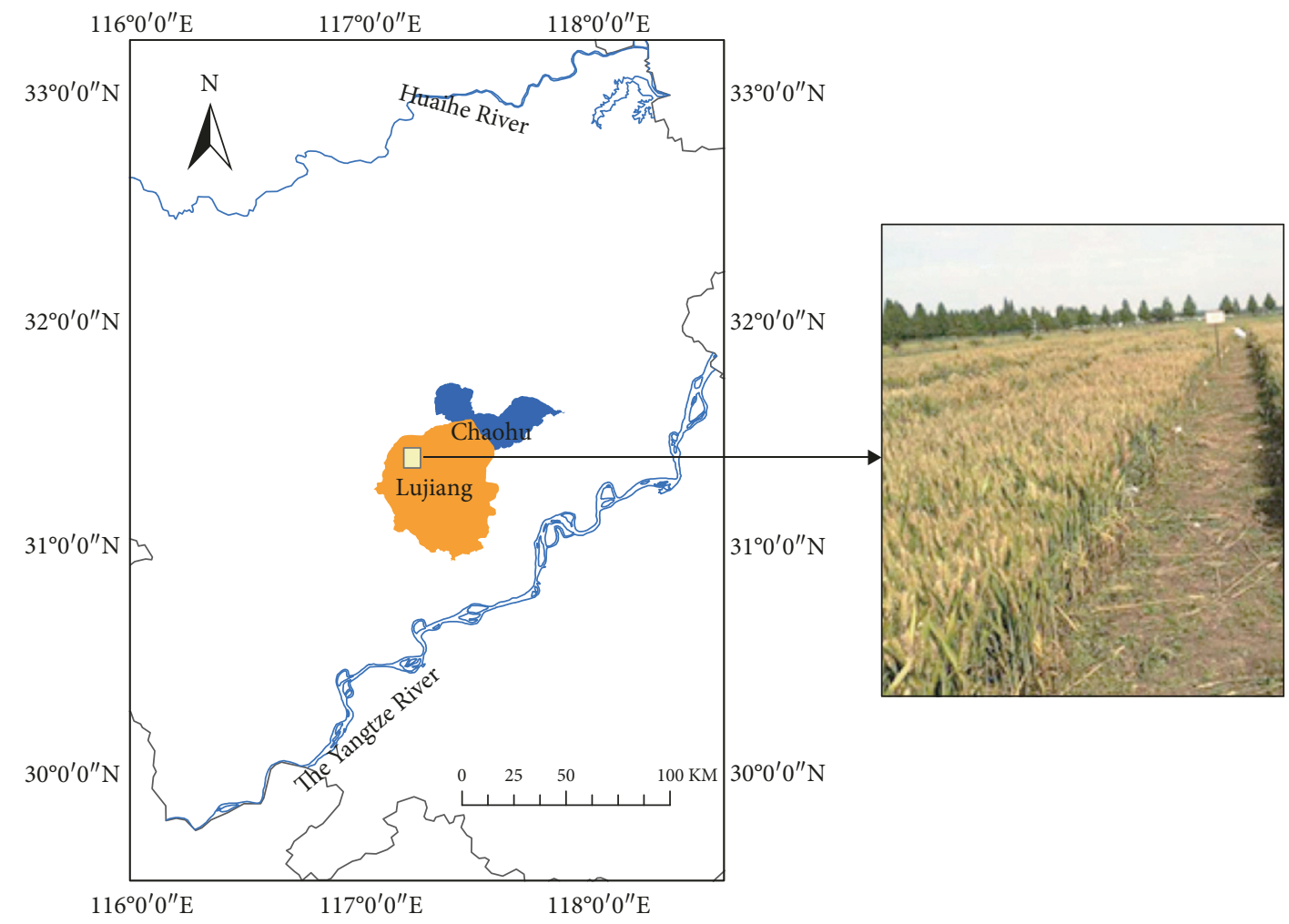

Figure 1: Location of the study site.

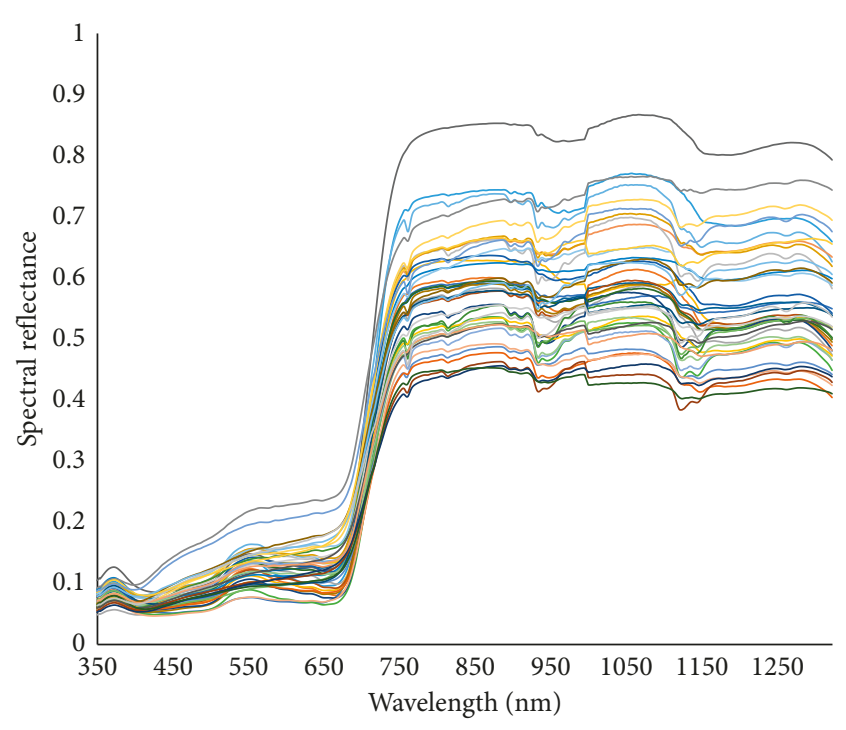

Figure 2: Spectral reflectance curves of 41 wheat ear samples.

2.4.2. Leave-One-Out Cross Validation. Leave-one-out cross validation was applied to verify the classification accuracy. Its main idea [12] is that one sample is first selected randomly from the $N$ samples, and the other $N-1$ samples are used as the training samples. A model will be obtained to verify the accuracy with the selected single data, so repeat $N$ times. The root mean square error (RMSE) was used to evaluate the model shown as follows [14]:

$$
\mathrm{RMSE}=\sqrt{\frac{\sum_{i=1}^{n}\left(y_{i}-y_{i}^{\wedge}\right)^{2}}{n}},
$$

where $y_{i}$ and $y_{i}^{\wedge}$ represent the measured value and the predicted value, respectively, and $n$ is the total number of samples. The smaller the RMSE is, the higher the prediction accuracy of the model is.

2.4.3. Selection of Vegetation Index and Differential Spectral Characteristics. Spectral indices are widely used for monitoring, analyzing, and mapping temporal and spatial variation in vegetation [15]. Spectral indices are the basis for wide applications in remote sensing-based crop management because they are highly correlated to biophysical and biochemical crop variables [16]. Infected crops can cause changes in pigment, water, morphology, structure, etc. Some indices can characterize these changes, for example, NDVI can reflect the growth of crops and NRI (nitrogen reflectance index) is a factor to study the nitrogen content of vegetation. We summarized the spectral features commonly used in crop stress through the literature review. A total of 22 spectral features including first-order differential spectral features and vegetation indices were selected (Table 1).

2.4.4. Unitary Linear Regression. The unitary linear regression is a relationship between an independent variable and a dependent variable. It is the simplest regression 
TABle 1: Definitions of vegetation indices and spectral differential characteristics.

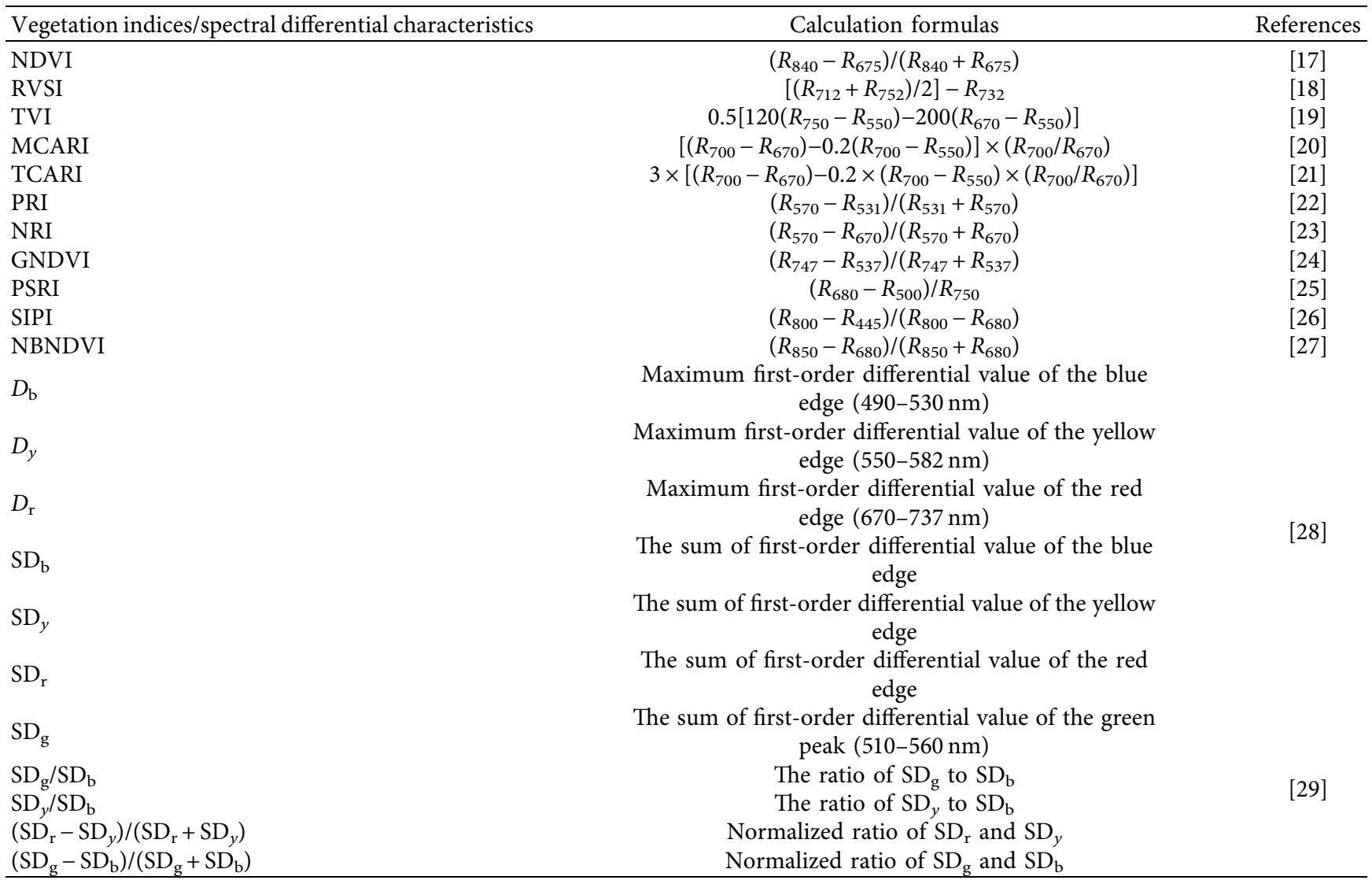

method and also the basis for learning other regression methods. The model of the linear regression is [30]

$$
y=a x+b
$$

where $y$ is the dependent variable, $x$ is the independent variable, and $a$ and $b$ are the regression constants.

2.4.5. Multiple Stepwise Regression. Multiple stepwise regression algorithm is often used for regression analysis of two or more independent variables and dependent variables. The main principle is to determine its importance by the $F$ test for each introduced variable. Meanwhile, the T-test is performed on the variables introduced into the model. When the first introduced variable is no longer significant for the dependent variable due to the introduction of new variables, the variable will be deleted. Only the important variable is retained in the regression model. Assuming there are $n$ independent variables $\left(x_{1}, x_{2}, \ldots, x_{n}\right)$ and $y$ is used as the dependent variable, then the multiple stepwise regression model is defined as follows [31]:

$$
y=a_{1} x_{1}+a_{2} x_{2}+\cdots+a_{n} x_{n}+a_{0},
$$

where $a_{i}(i=0,1, \ldots, n)$ is the pending regression constant.

\section{Results and Discussion}

3.1. Spectral Response Characteristics and Correlation Analysis. It can be seen from Figure 3 that with increasing disease levels, the spectral reflectance of scab-infected wheat decreases in the near-infrared region, while it increases in the visible region and the "green peak" and "red valley" gradually become gentle. This is because when the crop is infected by pathogens, it will cause many lesions, necrosis, or wilting in the leaves of the plants. The content and activity of the pigments are reduced, resulting in an increase in the reflectance of the visible region. Moreover, the water metabolism of infected plants will be disturbed, which will cause the water deficit of the leaves to some extent, and finally cause the change of reflectance in the near-infrared region [32].

It can be seen that the visible region is positively correlated with the severity of scab, and the near-infrared region is negatively correlated with the severity of scab (Figure 4). The band with a correlation coefficient greater than 0.5 in the visible region $(350-740 \mathrm{~nm}$ ) is $638-690 \mathrm{~nm}$, and the $674 \mathrm{~nm}$ has a highest correlation coefficient $(R=0.598)$, which is located in the red region. Because the photosynthesis ability of wheat is weakened due to the influence of scab, the correlation coefficient of chlorophyll absorption zone is increased. In addition, the correlation between the nearinfrared region $(760-1300 \mathrm{~nm})$ and the disease severity is generally low. The reason may be that the internal structure of the cell is destroyed and the reflectance is reduced. The spectral reflectance of $764 \mathrm{~nm}$ in the near-infrared region has a highest negative correlation $(R=-0.411)$. According to the aforementioned analysis, wheat scab has a response in the visible and near-infrared region. It showed a strong response 


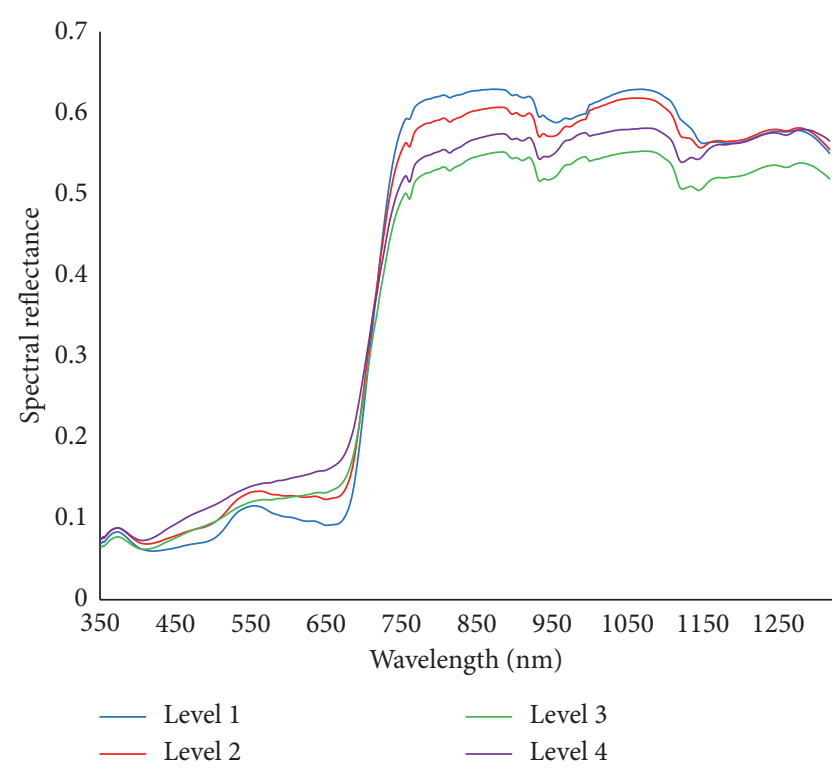

FIGURE 3: Spectral reflectance curves of wheat ear with different scab severity.

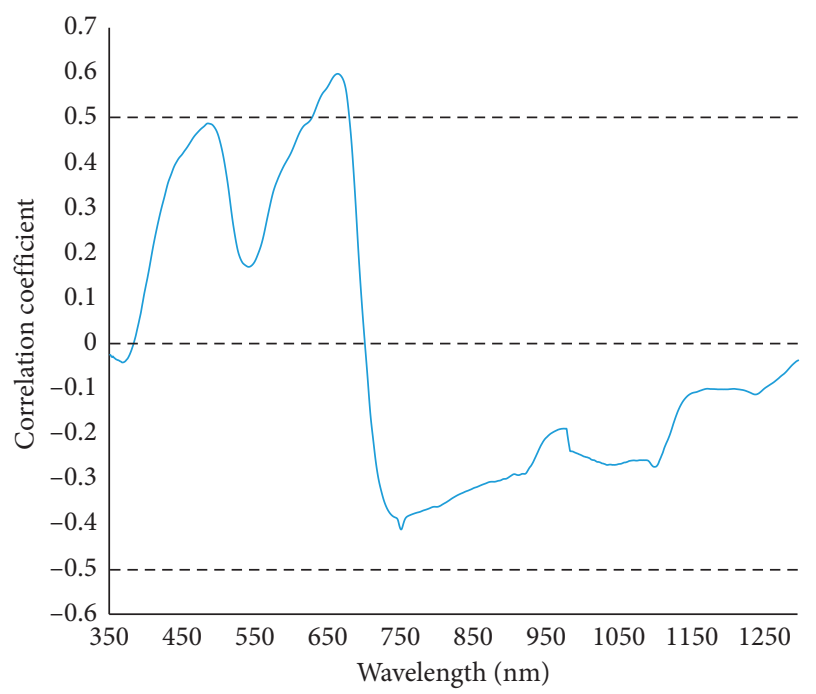

FIGURE 4: Curve of correlation coefficient between spectral reflectance and severity of disease.

in the visible region wavebands, but the correlation between the original spectral data and the severities of scab was not high.

3.2. Extraction of Sensitive Bands Based on Spectral Differentiation and Correlation Analysis. According to the firstorder differential spectral curve of four disease severities (Figure 5), they are different in the visible region of 450$740 \mathrm{~nm}$. As the disease level increases, we can see the differential values of $500-550 \mathrm{~nm}$ and $690-720 \mathrm{~nm}$ are gradually decreasing, as well as increasing in the region of $550-610 \mathrm{~nm}$. The regions of $500-550 \mathrm{~nm}$ and $550-610 \mathrm{~nm}$ are located on both the sides of the "green peak", indicating that the spectral reflectance curve become gentler in the two

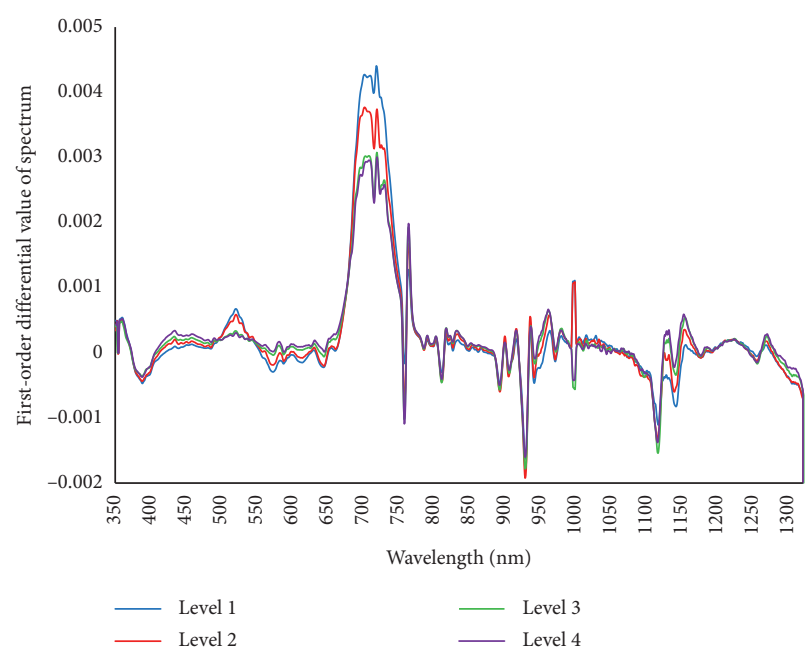

Figure 5: The first-order spectral differential curves of different disease severities $(350 \sim 1330 \mathrm{~nm})$.

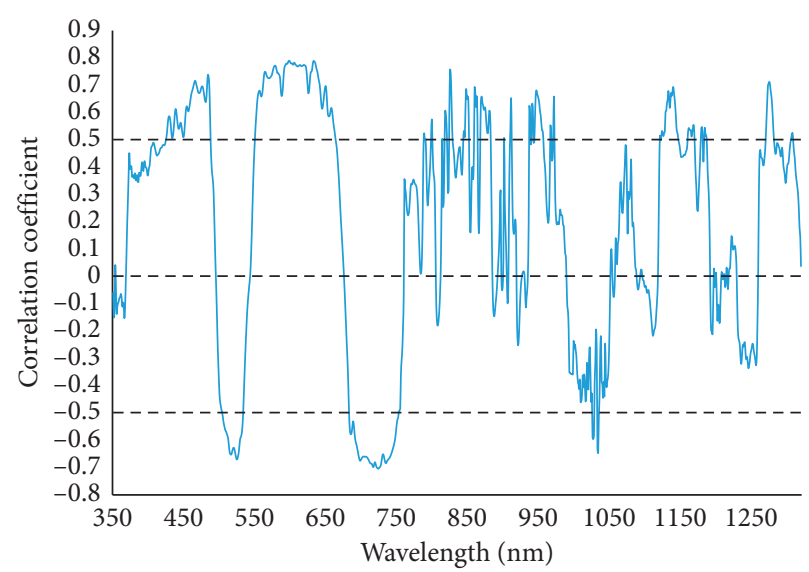

Figure 6: Curves of correlation coefficient between first-order differential spectrum and disease severity.

regions, which is consistent with the observation of the above spectral reflectance.

Correlation analysis was used to assess whether significant relationships existed between the first-order differential and the wheat scab disease levels (Figure 6). It could be found that $601 \mathrm{~nm}$ had the highest correlation $(R=0.79)$, which was located near the right side of the "green peak." All the correlation coefficients of $450-488 \mathrm{~nm}, 500-540 \mathrm{~nm}$, $552-667 \mathrm{~nm}$, and $687-756 \mathrm{~nm}$ were greater than 0.5 . The correlation between the first-order differential and the scab severity is better than that between the spectral reflectance and disease severity.

3.3. Construction of Wheat Scab Index. According to the above analysis, the correlation between the original spectral data and the disease is not significant, while the first-order spectral differential has a good correlation with wheat scab. There are four significant correlations between first-order differential and disease severity during the 450-488, 500$540,552-667$, and $687-756 \mathrm{~nm}$. The four wavelength ranges 
TABLE 2: Correlation of the first-order differential sum between four wavelength regions.

\begin{tabular}{lcccc}
\hline & $450-488 \mathrm{~nm}$ & $500-540 \mathrm{~nm}$ & $552-667 \mathrm{~nm}$ & $687-756 \mathrm{~nm}$ \\
\hline $450-488 \mathrm{~nm}$ & 1 & & & \\
$500-540 \mathrm{~nm}$ & -0.20839 & 1 & 1 & \\
$552-667 \mathrm{~nm}$ & 0.696811 & -0.81765 & -0.73471 & 1 \\
$687-756 \mathrm{~nm}$ & -0.43428 & 0.746772 & & 1 \\
\hline
\end{tabular}

TABLE 3: Unitary linear regression results of vegetation index and spectral differential characteristics.

\begin{tabular}{|c|c|c|c|c|}
\hline Vegetation indices/spectral differential characteristics & Regression equations & Fitting $R^{2}$ & Testing $R^{2}$ & RMSE \\
\hline $\mathrm{NDVI}^{* * *}$ & $y=-230.43 x+190.6$ & 0.66 & 0.62 & 15.90 \\
\hline $\mathrm{RVSI}^{* * *}$ & $y=2050.4 x+94.691$ & 0.46 & 0.41 & 18.97 \\
\hline TVI*** & $y=-3.1273 x+121.01$ & 0.51 & 0.46 & 18.04 \\
\hline MCARI*** & $y=-312.63 x+98.836$ & 0.56 & 0.52 & 17.03 \\
\hline TCARI*** & $y=-318.56 x+109.58$ & 0.32 & 0.26 & 21.10 \\
\hline $\mathrm{PRI}^{* * *}$ & $y=939.73 x+9.7802$ & 0.23 & 0.17 & 22.39 \\
\hline $\mathrm{NRI}^{* * *}$ & $y=218.71 x+46.115$ & 0.60 & 0.56 & 16.24 \\
\hline GNDVI $^{* * *}$ & $y=-255.18 x+205.82$ & 0.29 & 0.22 & 21.74 \\
\hline PSRI*** & $y=512.1 x-2.8595$ & 0.63 & 0.60 & 15.64 \\
\hline SIPI $^{* * *}$ & $y=246.27 x-241.23$ & 0.63 & 0.59 & 15.72 \\
\hline NBNDVI*** & $y=-237.09 x+190.71$ & 0.67 & 0.63 & 14.85 \\
\hline $\mathrm{SD}_{\mathrm{b}}^{* * *}$ & $y=-2863.5 x+86.013$ & 0.37 & 0.32 & 20.42 \\
\hline$D_{\mathrm{b}}{ }^{* * *}$ & $y=-74747 x+83.754$ & 0.46 & 0.41 & 18.89 \\
\hline $\mathrm{SD}_{y}{ }^{* * *}$ & $y=5342 x+49.266$ & 0.64 & 0.60 & 15.45 \\
\hline$D_{y}{ }^{* * *}$ & $y=227634 x+12.743$ & 0.29 & 0.10 & 23.56 \\
\hline $\mathrm{SD}_{\mathrm{r}}^{* * *}$ & $y=-438.57 x+123.95$ & 0.42 & 0.37 & 19.54 \\
\hline$D_{\mathrm{r}}^{* * *}$ & $y=-21667 x+126.12$ & 0.48 & 0.44 & 18.45 \\
\hline $\mathrm{SD}_{\mathrm{g}}^{* * *}$ & $y=-2696.1 x+85.146$ & 0.30 & 0.23 & 21.63 \\
\hline $\mathrm{SD}_{\mathrm{g}}^{\mathrm{g}} / \mathrm{SD}_{\mathrm{b}}{ }^{* * *}$ & $y=134.53 x-95.534$ & 0.26 & 0.16 & 22.82 \\
\hline $\mathrm{SD}_{y} / \mathrm{SD}_{\mathrm{b}}^{* * *}$ & $y=0.0089 x-0.3791$ & 0.61 & 0.58 & 15.88 \\
\hline$\left(\mathrm{SD}_{\mathrm{r}}-\mathrm{SD}_{y}\right) /\left(\mathrm{SD}_{\mathrm{r}}+\mathrm{SD}_{y}\right)^{* * *}$ & $y=-477.23 x+524.05$ & 0.63 & 0.60 & 15.53 \\
\hline$\left(\mathrm{SD}_{\mathrm{g}}-\mathrm{SD}_{\mathrm{b}}\right) /\left(\mathrm{SD}_{\mathrm{g}}+\mathrm{SD}_{\mathrm{b}}\right)^{* * *}$ & $y=304.84 x+38.803$ & 0.28 & 0.19 & 22.25 \\
\hline WSI $^{* * *}$ & $y=75.498 x+76.016$ & 0.73 & 0.70 & 13.41 \\
\hline
\end{tabular}

*** Correlation is significant at the 0.999 confidence level.

TABLE 4: Multiple stepwise regression model implemented in SPSS.

\begin{tabular}{lcccc}
\hline Model & $R$ & $R^{2}$ & Error estimation & Predictor variable \\
\hline 1 & 0.853 & 0.73 & 13.13 & Constant, WSI \\
2 & 0.865 & 0.75 & 12.80 & Constant, WSI, SDg/SDb \\
3 & 0.877 & 0.77 & 12.41 & Constant, WSI, SDg/SDb, NBNDVI \\
4 & 0.887 & 0.79 & 12.12 & Constant, WSI, SDg/SDb, NBNDVI, SDg \\
\hline
\end{tabular}

are located in the chlorophyll absorption zone, the blue edge, the yellow edge, and the red edge, respectively. When vegetation is infected by disease, the spectral reflectance of the chlorophyll absorption zone changes with the chlorophyll content. Relevant studies have shown [33] that the blue, yellow, and red edge of plants can be used to monitor crop pests and diseases. Therefore, this section attempts to use the first-order spectral differential sum of these four bands to construct the scab index. As these four wavebands are adjacent to each other, the sum of the first-order differential values of the four bands may have redundancy. Therefore, we make correlation analysis of the first-order differential sum of the four band intervals and choose the weakly correlated bands of $450-488 \mathrm{~nm}$ and $500-540 \mathrm{~nm}$ to construct the wheat scab index (WSI). The correlation coefficient between different wavebands and the method to construct WSI are shown in Table 2 and formula (6), respectively.

$$
\mathrm{WSI}=\frac{\mathrm{SD}_{450-488}-\mathrm{SD}_{500-540}}{\mathrm{SD}_{450-488}+\mathrm{SD}_{500-540}}
$$

3.4. Unitary Linear Regression. The purpose of this experiment is to analyze the sensitivity of existing vegetation indices and spectral differential characteristics to wheat scab under linear regression conditions and to verify the applicability of the proposed scab index. Table 3 summarizes the unitary linear regression responses of all spectral indices (including WSI) to wheat scab disease. We found that the selected 23 indices manifested excellent potential for discriminating wheat scab $(p<0.001)$. However, not all the 


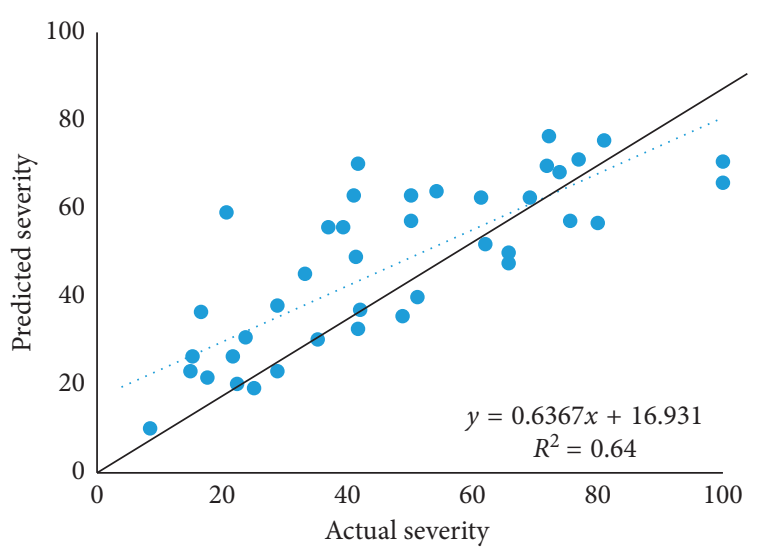

(a)

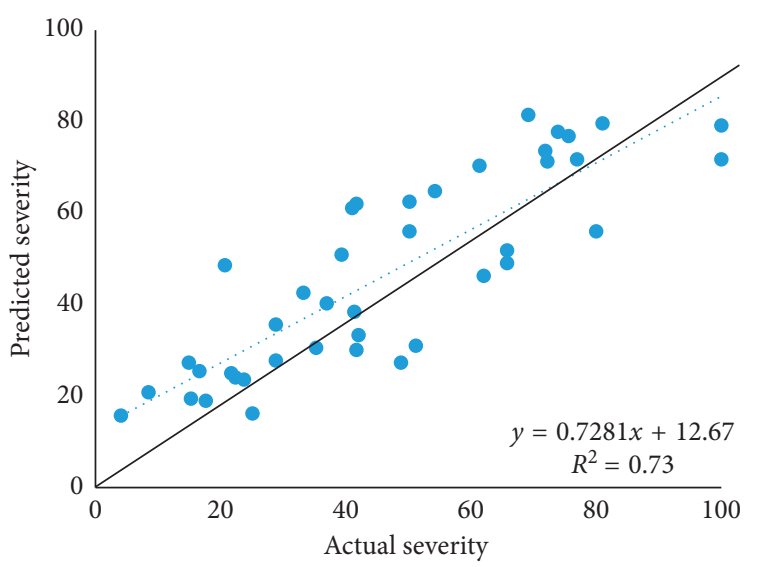

(c)

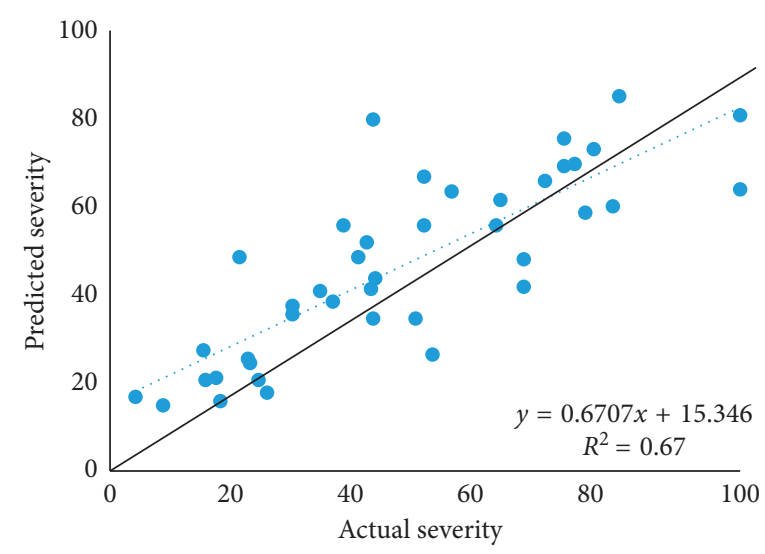

(b)

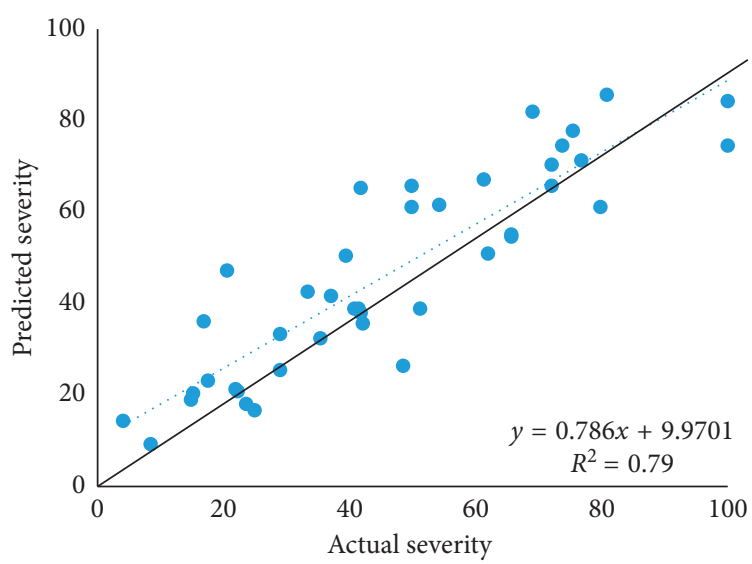

(d)

FIgURE 7: Regression model. Unitary linear regression model constructed by (a) $\mathrm{SD}_{y}$ and disease severities, (b) NBNDVI and disease severities, and (c) WSI and disease severities and (d) multiple stepwise regression model.

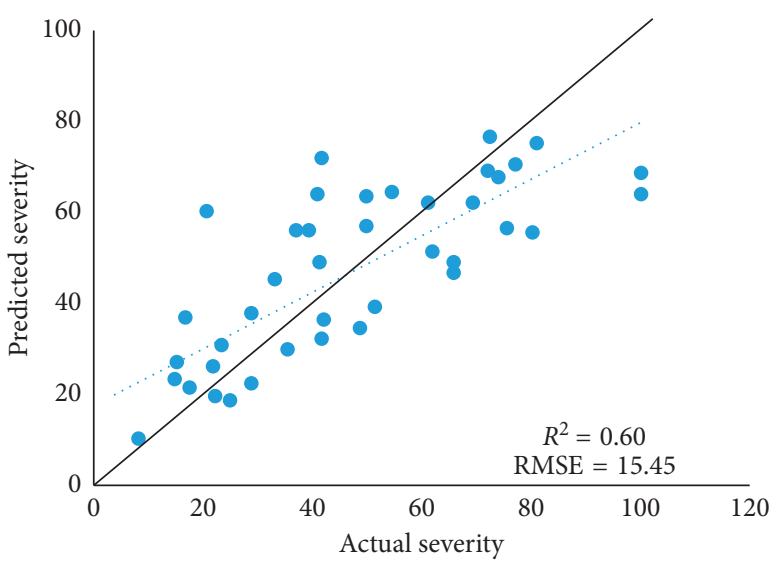

(a)

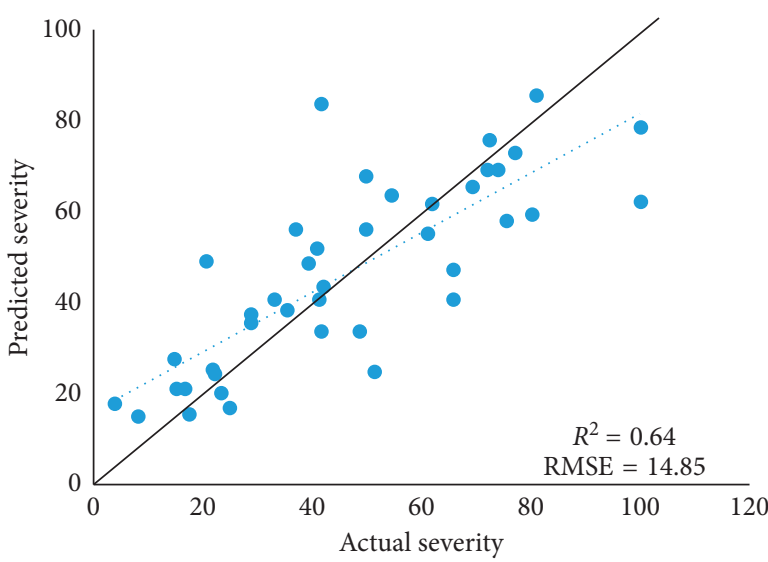

(b)

Figure 8: Continued. 


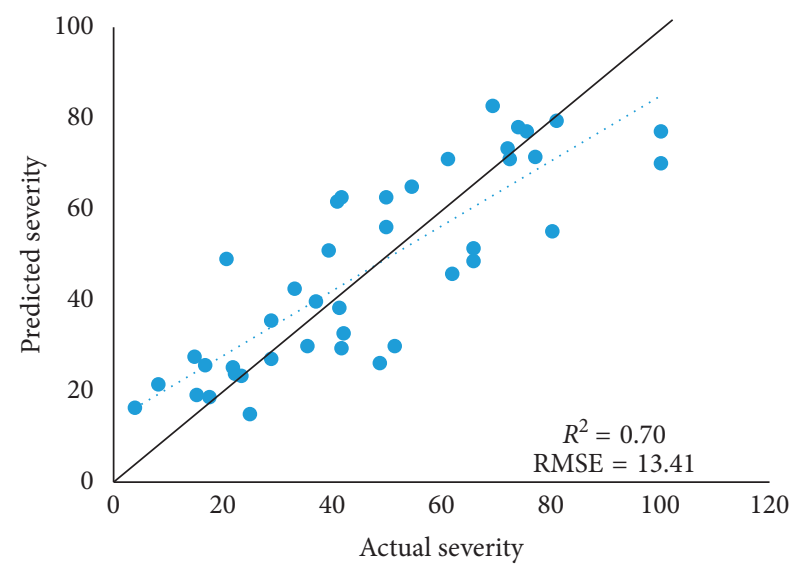

(c)

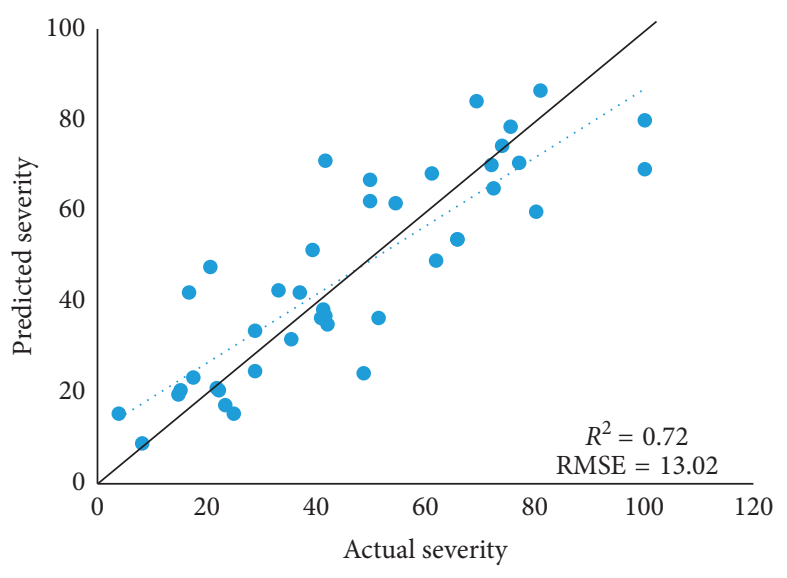

(d)

Figure 8: Leave-one-out cross validation for (a) $\mathrm{SD}_{y}$, (b) NBNDVI, (c) WSI, and (d) multiple stepwise regression.

selected spectral indices were able to significantly discriminate wheat scab. Specifically, WSI showed the highest fitting $R^{2}$ of 0.73 , followed by NBNDVI, NDVI, and $\mathrm{SD}_{y}$ with fitting $R^{2}$ of $0.67,0.66$, and 0.64 , respectively. It can be found that most fitting $R^{2}$ are not high. Leave-one-out cross validation was used for the accuracy verification for the regression results of all indices (Table 3 ). The results prove that WSI has the highest accuracy (testing $R^{2}=0.70 ; \quad \operatorname{RMSE}=13.41$ ), which indicates it can perform well in identifying wheat scab of different levels on the ear scale.

3.5. Multiple Stepwise Regression. Related studies have shown that the model established by multiple variables is better than that by single variable [34]. The multiple stepwise regression statistical method was used to calculate the relationship between spectral indices and disease severities. Taking all the 23 spectral indices as independent variables and the disease severity as the dependent variable, it can be known that the final variables of the model are WSI, $\mathrm{SD}_{\mathrm{g}}$ / $\mathrm{SD}_{\mathrm{b}}$, NBNDVI, and $\mathrm{SD}_{\mathrm{g}}$ (Table 4). Then, the multivariate stepwise regression equation is obtained as follows:

$$
\begin{aligned}
y= & 30.627 \text { WSI }-82.765\left(\frac{\mathrm{SD}_{\mathrm{g}}}{\mathrm{SD}_{\mathrm{b}}}\right)-192.218 \mathrm{NBNDVI} \\
& -984.01 \mathrm{SD}_{\mathrm{g}}+276.882 .
\end{aligned}
$$

The multiple regression model was compared with three unitary regression models with high fitting $R^{2}$ (Figure 7). We find that the multiple regression model produced the highest fitting $R^{2}$ of 0.79 and more even distribution. To further validate the ability of the model constructed by WSI, $\mathrm{SD}_{\mathrm{g}} /$ $\mathrm{SD}_{\mathrm{b}}, \mathrm{NBNDVI}$, and $\mathrm{SD}_{\mathrm{g}}$ to detect wheat scab disease, we used leave-one-out cross validation; scatter plots of the relationship between the actual severity and predicted severity are shown in Figure 8. The multiple stepwise regression showed a testing $R^{2}$ of 0.72 and an RMSE of 13.02, respectively, indicating that the integrated model based on WSI, $\mathrm{SD}_{\mathrm{g}} / \mathrm{SD}_{\mathrm{b}}, \mathrm{NBNDVI}$, and $\mathrm{SD}_{\mathrm{g}}$ has a better inversion effect on the severity of disease than the single variable.

\section{Conclusions}

The timely monitoring of wheat scab disease is critical for agricultural management. By analyzing the correlation between first-derivate spectra and corresponding disease severity levels, two sensitive wavebands $(450-488 \mathrm{~nm}$ and $500-540 \mathrm{~nm}$ ) were selected. Subsequently, a new index (WSI) was developed for detecting and monitoring wheat scab at the ear scale. Compared with other common spectral indices, WSI has excellent performance with the fitting $R^{2}$ of 0.73 , testing $R^{2}$ of 0.70 , and RMSE of 13.01 , respectively. Moreover, the multiple regression model is more conducive to the identification of scab than univariate regression models. Our study can provide the technical support for the early diagnosis and management of wheat scab.

\section{Data Availability}

The data used to support the findings of this study are available from the corresponding author upon request.

\section{Conflicts of Interest}

The authors declare that they have no conflicts of interest.

\section{Acknowledgments}

The work presented here was supported by the Anhui Provincial Science and Technology Project (16030701091), Natural Science Research Project of Anhui Provincial Education Department (KJ2019A0030), and National Natural Science Foundation of China (31971789).

\section{References}

[1] R. Mao, Study on Application of Partial Least Squares Method Wheat Scab Forecasting-A Case Study of Anhui Tongcheng Wheat Scab, Anhui Agricultural University, Hefei, China, 2016.

[2] J. Zhang, Y. J. Yi, J. S. Wang, S. H. Chen, and G. L. Ling, "Research progress of control techniques on wheat scab," China Plant Protection, vol. 34, no. 1, pp. 24-28, 2014. 
[3] S. Li, Z. C. Guo, C. Wang, T. E. Chen, and Z. G. Yuan, "Application of information technology in monitoring and early warning of crop diseases and insect pests: a review," Jiangsu Agricultural Sciences, vol. 46, no. 22, pp. 1-6, 2018.

[4] T. Kobayashi, E. Kanda, K. Kitada, K. Ishiguro, and Y. Torigoe, "Detection of rice panicle blast with multispectral radiometer and the potential of using airborne multispectral scanners," Phytopathology, vol. 91, no. 3, pp. 316-323, 2001.

[5] I. Filella and J. Penuelas, "The red edge position and shape as indicators of plant chlorophyll content, biomass and hydric status," International Journal of Remote Sensing, vol. 15, no. 7, pp. 1459-1470, 1994.

[6] Y. L. Tang and J. F. Huang, "Study on hyperspectral remote sensing in agriculture," Remote Sensing Technology and Application, vol. 16, no. 4, pp. 248-251, 2011.

[7] D. Bandyopadhyay, D. Bhavsar, K. Pandey, S. Gupta, and A. Roy, "Red edge index as an indicator of vegetation growth and vigor using hyperspectral remote sensing data," Proceedings of the National Academy of Sciences, India Section A: Physical Sciences, vol. 87, no. 4, pp. 879-888, 2017.

[8] S. Graeff, J. Link, and W. Claupein, "Identification of powdery mildew and take-all disease in wheat by means of leaf reflectance measurements," Central European Journal of Biology, vol. 1, no. 2, pp. 275-288, 2006.

[9] M. Y. Huang, Monitoring of Winter Wheat Stripe Rust Using Hyperspectral Remote Sensing Data, Anhui Agricultural University, Hefei, China, 2004.

[10] S. R. Delwiche and M. S. Kim, "Hyperspectral imaging for detection of scab in wheat," Proceedings of SPIE-The International Society for Optical Engineering, vol. 4203, pp. 13-20, 2000.

[11] C. Bravo, D. Moshou, J. West, A. McCartney, and H. Ramon, "Early disease detection in wheat fields using spectral reflectance," Biosystems Engineering, vol. 84, no. 2, pp. 137-145, 2003.

[12] Q. Zheng, W. J. Huang, X. M. Cui et al., "Identification of wheat yellow rust using optimal three-band spectral indices in different growth stages," Sensors, vol. 19, no. 1, 2018.

[13] J. B. Jiang, Y. H. Chen, and W. J. Huang, "Using hyperspectral derivative index to monitor winter wheat disease," Spectroscopy and Spectral Analysis, vol. 27, no. 12, pp. 2475-2479, 2007.

[14] N. Wu, J. A. Liu, R. S. Yan, G. Y. Zhou, and L. Zhang, "Spectral reflectance feature in canopy of pinus massoniana cercospora needle blight and severity level inversion," Chinese Agricultural Science Bulletin, vol. 28, no. 4, pp. 51-57, 2012.

[15] A. A. Gitelson, Y. J. Kaufman, R. Stark, and D. Rundquist, "Novel algorithms for remote estimation of vegetation fraction," Remote Sensing of Environment, vol. 80, no. 1, pp. 76-87, 2002.

[16] H. AL-Saddik, J.-C. Simon, and F. Cointault, "Development of spectral disease indices for "flavescence dorée" grapevine disease identification," Sensors, vol. 17, no. 12, p. 2772, 2017.

[17] J. Q. Ren, S. R. Wu, B. Liu, Z. X. Chen, X. R. Liu, and H. Li, "Retrieving winter wheat above-ground dry biomass based on hyperion hyperspectral imagery," Transactions of the Chinese Society for Agricultural Machinery, vol. 49, no. 4, pp. 199-211, 2018.

[18] A. Davoud, M. Mohammad, and H. Alfredo, "Evaluating the effect of different wheat rust disease symptoms on vegetation indices using hyperspectral measurements," Remote Sensing, vol. 6 , no. 6 , pp. 5107-5123, 2014.

[19] N. H. Broge and E. Leblanc, "Comparing prediction power and stability of broadband and hyperspectral vegetation indices for estimation of green leaf area index and canopy chlorophyll density," Remote Sensing of Environment, vol. 76, no. 2, pp. 156-172, 2001.
[20] C. Daughtry, C. L. Walthall, M. S. Kim, E. B. de Colstoun, and J. E. McMurtrey, "Estimating corn leaf chlorophyll concentration from leaf and canopy reflectance," Remote Sensing of Environment, vol. 74, no. 2, pp. 229-239, 2000.

[21] W. J. Huang, M. Y. Huang, L. Y. Liu, J. H. Wang, C. J. Zhao, and J. D. Wang, "Inversion of the severity of winter wheat yellow rust using proper hyper spectral index," Transactions of the Chinese Society of Agricultural Engineering, vol. 21, no. 4, pp. 97-103, 2005.

[22] T. S. Magney, L. A. Vierling, J. U. H. Eitel, D. R. Huggins, and S. R. Garrity, "Response of high frequency photochemical reflectance index (PRI) measurements to environmental conditions in wheat," Remote Sensing of Environment, vol. 173, pp. 84-97, 2016.

[23] X. Yao, S.-P. Tang, W.-X. Cao, Y.-C. Tian, and Y. Zhu, "Estimating the nitrogen content in wheat leaves by nearinfrared reflectance spectroscopy," Chinese Journal of Plant Ecology, vol. 35, no. 8, pp. 844-852, 2011.

[24] J. J. Lu, L. G. Sun, and W. J. Huang, "Research progress in monitoring and forecasting of crop diseases and pests by remote sensing," Remote Sensing Technology and Application, vol. 34, no. 1, pp. 21-32, 2019.

[25] Y. C. Tian, X. Yao, J. Yang, W. X. Cao, D. B. Hannaway, and Y. Zhu, "Corrigendum to "Assessing newly developed and published vegetation indices for estimating rice leaf nitrogen concentration with ground- and space-based hyperspectral reflectance" [field crops res. 120 (2011) 299-310]," Field Crops Research, vol. 121, no. 3, p. 464, 2011.

[26] J. Penuelas, F. Baret, and I. Filella, "Semi-empirical indices to assess carotenoids/chlorophyll a ratio from leaf spectral reflectance," Photosynthetica, vol. 31, no. 2, pp. 221-230, 1995.

[27] P. S. Thenkabail, R. B. Smith, and E. De Pauw, "Hyperspectral vegetation indices and their relationships with agricultural crop characteristics," Remote Sensing of Environment, vol. 71, no. 2, pp. 158-182, 2000.

[28] P. Gong, R. Pu, and R. C. Heald, "Analysis of in situ hyperspectral data for nutrient estimation of giant sequoia," International Journal of Remote Sensing, vol. 23, no. 9, pp. 1827-1850, 2002.

[29] J. B. Jiang, Y. H. Chen, and W. J. Huang, "Study on hyperspectra estimation of pigment contents in canopy leaves of winter wheat under disease stress," Spectroscopy and Spectral Analysis, vol. 27, no. 7, pp. 1363-1367, 2007.

[30] J. J. Zhang and Y. H. Ge, "More efficient methods among commonly used robust estimation methods for robust unitary linear regression," Advanced Materials Research, vol. 712-715, pp. 2493-2496, 2013.

[31] X. Jin, G. Yang, X. Xu et al., "Combined multi-temporal optical and radar parameters for estimating LAI and biomass in winter wheat using HJ and RADARSAR-2 data," Remote Sensing, vol. 7, no. 10, pp. 13251-13272, 2015.

[32] J. C. Zhang, L. Yuan, J. H. Wang, J. H. Luo, S. Z. Du, and W. J. Huang, "Research progress of crop diseases and pets monitoring based on remote sensing," Transactions of the Chinese Society of Agricultural Engineering, vol. 28, no. 20, pp. 1-11, 2012.

[33] J. J. Lu, W. J. Huang, J. B. Jiang, and J. C. Zhang, "Comparison of wavelet features and conventional spectral features on estimating severity of stripe rust in winter wheat," Journal of Triticeae Crops, vol. 35, no. 10, pp. 1456-1461, 2015.

[34] H. Fang, H. Y. Song, F. Cao, Y. He, and Z. J. Qiu, "Study on the relationship between spectral properties of oilseed rape leaves and their chlorophyll content," Spectroscopy and Spectral Analysis, vol. 27, no. 9, pp. 1731-1734, 2007. 

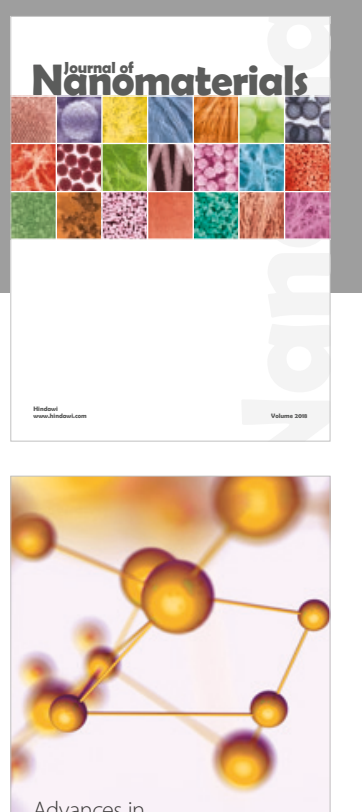

Physical Chemistry
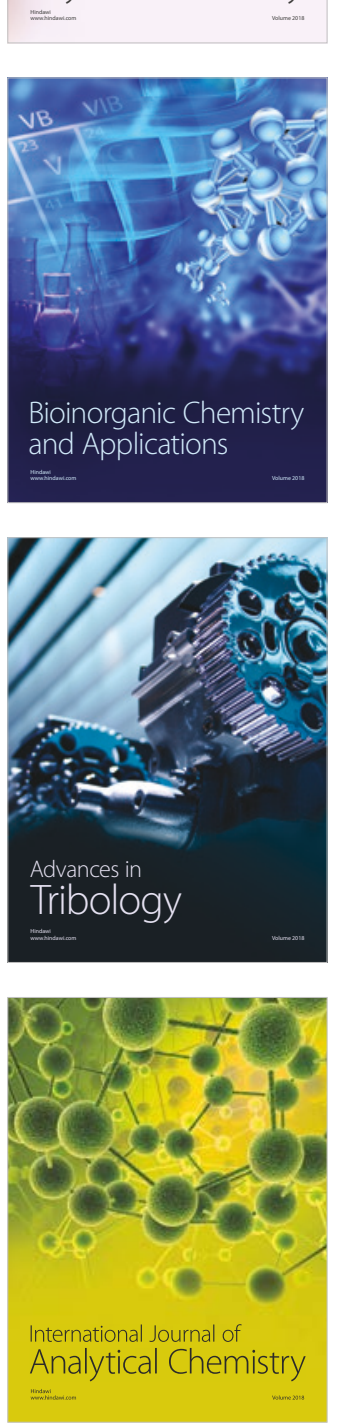

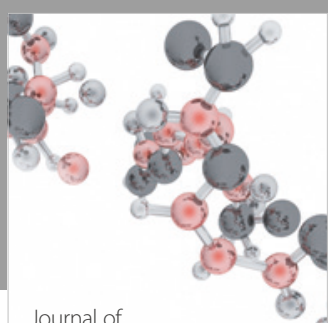

Analytical Methods

in Chemistry

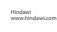

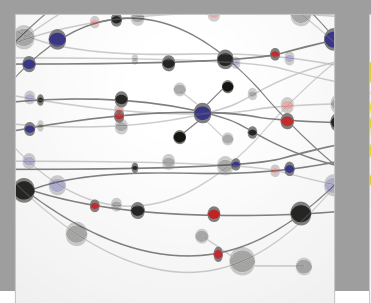

The Scientific World Journal

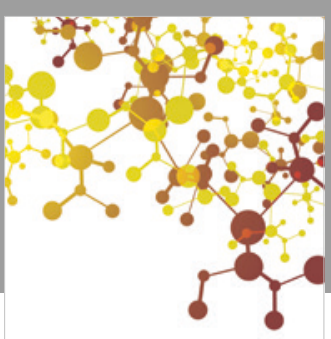

Journal of

Applied Chemistry
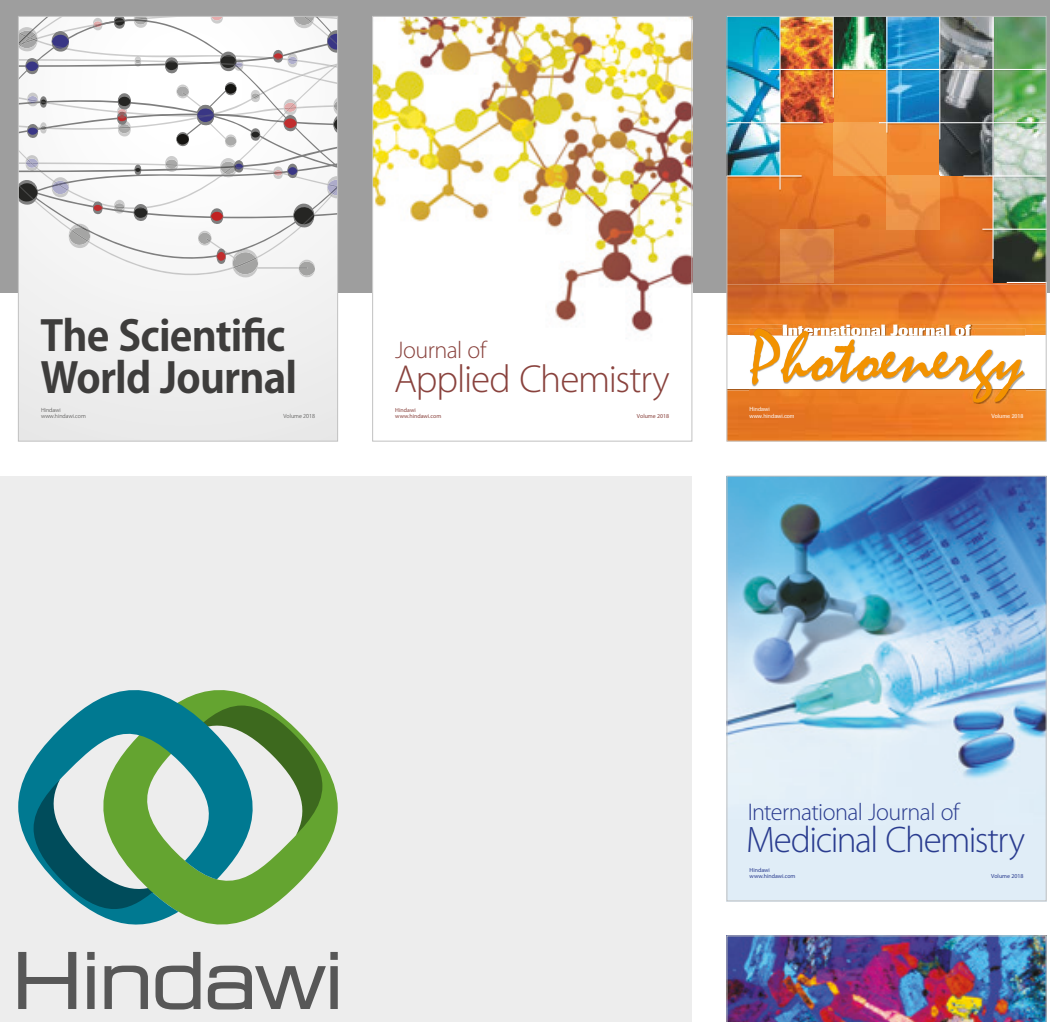

Submit your manuscripts at

www.hindawi.com
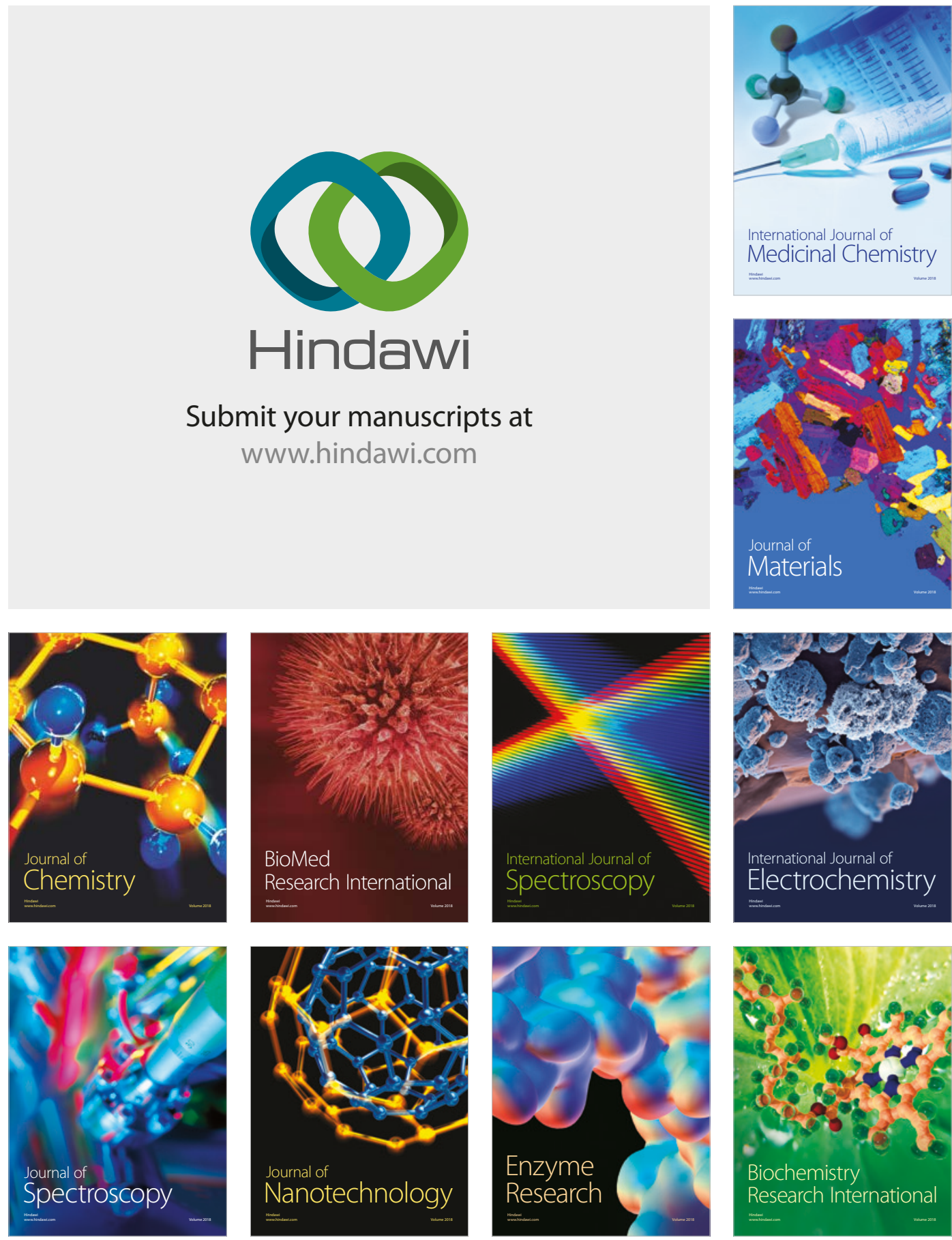
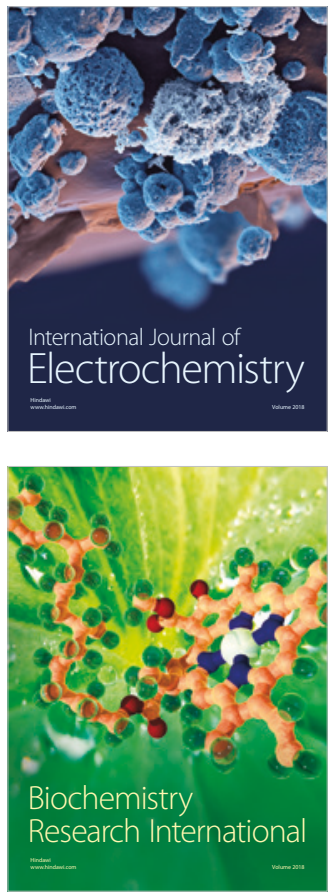